\title{
Análise do processo de registro em Signwriting: contribuições para a fonologia da Libras
}

\author{
Débora Campos Wanderley ${ }^{1}$ \\ Janine Soares de Oliveira ${ }^{2}$
}

\section{Resumo}

O presente texto é um recorte de pesquisa cujo foco foi a identificação de padrões para o registro em escrita de sinais. Pretende-se contribuir para as discussões no campo da fonologia investigando se existe padrão na sequência escolhida para registro dos glifos (símbolos) do sinal escrito. Para isso foram coletados dados em um experimento realizado com quatro participantes, que consistiu na escrita de sinais da Libras usando o sistema SignWriting. A pesquisa fundamenta-se em resultados encontrados principalmente por Karnopp (1999) e Nobre (2011), e retoma a discussão da simultaneidade e sequencialidade observada por Stokoe (1978) e Liddell e Johnson (1989). A análise do processo de registro da escrita do sinal identificou que, apesar de a configuração de mão ser considerada como parâmetro de destaque na descrição fonológica dos sinais, nos casos em que existe o toque em alguma região do corpo o primeiro parâmetro registrado é o ponto de articulação.

Palavras-chave: signwriting; libras; fonologia; sequencialidade

${ }_{1}$ Professora de Letras Libras da Universidade Federal de Santa Catarina (UFSC), Florianópolis, Brasil - E-mail: deboraufsclibras@gmail.com

2 Professora de Letras Libras da Universidade Federal de Santa Catarina (UFSC), Florianópolis, Brasil - E-mail: janinemat@gmail.com 


\section{Abstract}

This paper is the result of a part of a research whose focus was the identification of patterns for the notation in the SignWriting system. We intend to contribute to the discussions in the field of phonology by investigating whether there is a pattern in the chosen sequence for recording the glyphs (symbols) of the written signs. For this, data were collected in an experiment conducted with four participants, which consisted of writing Libras signs using the SignWriting system. The main research is based on results found mainly by Karnopp (1999) and Nobre (2011), and retakes the discussion of simultaneity and sequentiality observed by Stokoe (1978) and Liddell and Johnson (1989). The analysis of the SignWriting process identified that, although hand configuration is considered the prominent parameter in the phonological description of the signs, in cases where there is touch in some part of the body the first parameter recorded is the location.

Keywords: signwriting; libras; phonology; sequentiality

\section{Introdução}

Diferentemente da língua portuguesa escrita - que é alfabética e representa os fonemas, cuja base são os sons produzidos pelo aparelho fonador -, a escrita de sinais utiliza símbolos, ou glifos ${ }^{3}$ (BIANCHINI

3 Pesquisadores de SignWriting, como Bianchini e Borgia (2012), propõem o uso do termo "glifo", no sentido da tipografia, para se referir aos símbolos registrados na escrita do sinal. Stumpf e Wanderley (2016) seguem essa linha e também utilizam o termo glifo. Entende-se que glifo, no âmbito da pesquisa em Escrita de Sinais, é um símbolo elementar dentro de um conjunto de símbolos convencionados que contribuem de alguma forma para um significado específico do que está escrito. 
e BORGIA, 2012), correspondentes aos parâmetros visuais ${ }^{4}$ para representar as configurações de mão, os movimentos, as expressões faciais, locações e as orientações de mãos das línguas de sinais (LSs).

A escrita de sinais tem se desenvolvido consideravelmente desde que foi proposta por Valerie Sutton, em 1974. As análises linguísticas realizadas a partir do registro escrito das línguas de sinais (NOBRE, 2011; GALEA, 2014) fornecem informações relevantes sobre a estrutura fonológica das línguas.

Cada língua, em seu registro escrito, tem um conjunto de restrições que definem uma palavra ou, no caso das línguas de sinais, o sinal ${ }^{5}$. Essas restrições são estabelecidas em termos de ordenação da sequência de glifos para registro, tais como as sequências dos parâmetros das línguas de sinais.

Ao registrar as línguas de sinais na forma escrita observa-se o uso de um tempo maior do que o necessário para a realização do sinal - assim como nas línguas orais, falar é mais rápido do que escrever pela necessidade de se registrar todos os parâmetros para formar um determinado sinal. Enquanto na leitura, tal como nas línguas orais, os glifos de um sinal escrito são decodificados de forma holística.

Neste artigo apresenta-se um recorte de investigação cujo foco foi a identificação de padrões para o registro em escrita de sinais.

O sistema de escrita de sinais utilizado na pesquisa foi o SignWriting, conforme proposto por Sutton (1995), que consiste em um conjunto de

${ }^{4} \mathrm{Na}$ presente pesquisa denominam-se "parâmetros visuais" as estruturas que seriam, de certa forma, análogas aos fonemas das línguas orais. Assim como as línguas orais têm um registro alfabético convencionado que possibilita a associação dos sons (fonemas) com glifos escritos, entende-se que as línguas de sinais apresentam o mesmo potencial, ou seja, é possível convencionar glifos que representem os "parâmetros visuais do sinal" para o registro escrito da língua.

${ }^{5}$ Segundo Zeshan (2002), os linguistas de línguas de sinais geralmente não falam sobre "palavras". O "sinal" é utilizado para se referir a unidades equivalentes às palavras nas LSs. Ainda segundo a pesquisadora, a justificativa inicial para dizer que palavra e sinal estão situados em um nível equivalente de organização linguística baseia-se no modo como sinalizantes percebem os sinais de sua língua. Fato também observado por Aldrete (2008) e Brentari e Wilbur (2008), por exemplo. 
glifos e possibilita uma escrita visual direta por meio da qual é possível ler e escrever as línguas de sinais sem a necessidade de tradução para uma língua oral.

Assim como o alfabeto latino, que é usado para escrever o português, o inglês, o francês e tantas outras línguas orais, o conjunto de glifos utilizado no SignWriting, é internacional e pode ser usado para escrever qualquer língua de sinais do mundo (SUTTON, 2011).

A partir dessas informações iniciais considera-se pertinente registrar que a presente investigação foi guiada por algumas questões principais. A primeira:

1. A escrita de um sinal no sistema SignWriting é simultânea ou sequencial?

Essa primeira pergunta, a princípio, indicava não carecer de análise aprofundada, visto que parece improvável a existência de alguém que escreva uma parte de um dos glifos para representar movimento (uma seta, por exemplo), pare, e comece a escrever outro glifo para representar a configuração de mão, pare na metade e volte para retomar a escrita do movimento; assim fazendo de modo a não registrar um glifo por vez. Mais improvável ainda seria alguém escrevendo diferentes glifos ao mesmo tempo.

Portanto, por razões lógicas, considerou-se que o sujeito que escreve o sinal precisa adotar uma sequência de registro e, assim, a primeira pergunta foi transformada em:

2. Existe padrão na sequência escolhida para registro dos glifos de um sinal escrito? Ou ainda, diferentes sujeitos adotam a mesma sequência de registro de glifos?

Com o objetivo de buscar respostas para essas perguntas, foram coletados dados de adultos sinalizantes (quatro estudantes surdas entre 18 e 28 anos) que possuíam experiência no registro em escrita de sinais utilizando o sistema SignWriting. 
Antes de discutir os dados, apresentar-se-ão algumas reflexões sobre fonologia e escrita de sinais, com base nos estudos desenvolvidos pelos pesquisadores Stokoe (1978/1960), Karnopp (1999) e Nobre (2011). A revisão de literatura, principalmente desses autores, e a reflexão sobre a prática de ensino da escrita de sinais corroboraram com o entendimento da relevância da pesquisa sobre o registro escrito dos sinais da Libras.

\section{Organização fonológica das línguas de sinais e conexões com a escrita de sinais}

Nesta seção apresenta-se a organização fonológica das línguas de sinais, comparando a língua sinalizada propriamente dita com seu registro escrito, com objetivo de subsidiar a discussão sobre padrões de ordenação do registro escrito dos sinais da Libras.

William Stokoe, linguista americano, foi um dos pioneiros na descrição linguística de uma língua de sinais. O nome desse pesquisador, assim como o ano 1960, é reconhecido amplamente por pesquisadores da área de linguística das línguas de sinais. Foi em 1960 que Stokoe comprovou, a partir de seus estudos da ASL (do inglês American Sign Language), que as línguas de sinais seriam línguas naturais. Nessa época havia registro de imagem, mas as filmagens exigiam muitos equipamentos, que custavam caro e geravam vídeos pesados. Por isso, Stokoe buscou uma estratégia para registrar a ASL através de uma escrita própria, buscando comprovar que a língua de sinais atendia a todos os critérios linguísticos de uma língua natural. O sistema desenvolvido por Stokoe ficou conhecido como "Sistema Notacional de Stokoe". Esse registro escrito possibilitou o reconhecimento de uma organização fonológica e morfológica da ASL.

Para o desenvolvimento do sistema, Stokoe propôs um esquema linguístico estrutural para analisar a formação dos sinais, e propôs a decomposição de sinais na ASL em três principais aspectos, que não 
carregariam significados isoladamente. Usando a nomenclatura atual, seriam equivalentes a:

a. Configuração de mão (CM)

b. Locação da mão (L)

c. Movimento da mão (M)

Esses aspectos são vistos por alguns pesquisadores como equivalentes aos fonemas das línguas orais (LOs). Sobre isso, as autoras Quadros e Karnopp (2004) explicam:

A ideia de que CM, L e M são unidades mínimas (fonemas) que constituem morfemas nas línguas de sinais, de forma análoga aos fonemas que constituem os morfemas nas línguas orais, começou a prevalecer. Entretanto, a principal diferença estabelecida entre línguas de sinais e línguas orais foi a presença de ordem linear (sequência horizontal no tempo) entre os fonemas das línguas orais e sua ausência nas línguas de sinais, cujos fonemas são articulados simultaneamente (QUADROS; KARNOPP, 2004, p. 49).

A questão da simultaneidade e da sequencialidade foi considerada em diferentes perspectivas pelos pesquisadores. Para ilustrar a ideia de que os fonemas são articulados simultaneamente, as autoras reproduzem o esquema proposto por Hulst (1993, p. 210) (figura 1):

Figura 1 - Esquema proposto por Hulst (1993) para representar a sequencialidade nas línguas orais e simultaneidade nas línguas de sinais

\section{Lingua Oral}
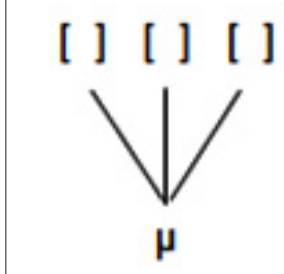

Lingua de Sinais

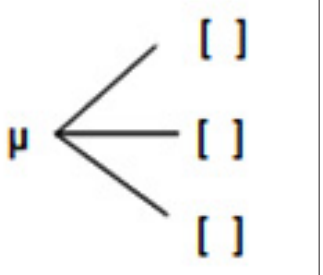

Nota explicativa: Alinhamento horizontal $=$ sucessão temporal; Alinhamento vertical $=$ simultaneidade temporal; $\mu=$ morfema; [ ] = um fonema ou conjunto de especificações. 
No entanto, nas pesquisas de Liddell (1984) e Liddell e Jonhson (1989), por exemplo, considera-se um modelo sequencial de descrição da ASL, uma proposta que descreve os sinais com base em movimento e suspensão. Do mesmo modo, Karnopp (1999) utiliza como referência para descrição de seus dados o modelo sequencial proposto por Hulst.

A diferença dos modelos está no papel do movimento. No modelo proposto por Liddell (1984) e Liddell e Johnson (1989), o movimento é uma unidade primitiva, enquanto no modelo proposto por Hulst (1993), o movimento é o resultado de uma mudança na configuração de mão, na orientação ou na locação. Kooji (1997 apud Karnopp, 1999) classifica a primeira proposta como modelo LML (Locação-Movimento-Locação) e a segunda como N-Mov ("No-moviment models").

Além de apresentar a discussão sobre o papel do movimento na constituição/descrição dos sinais, Karnopp (1999) estabelece que “os articuladores primários das línguas de sinais são as mãos, que se movimentam no espaço em frente ao corpo e articulam sinais em determinadas locações neste espaço" (KARNOPP, 1999, p. 30).

Em sua pesquisa, a autora selecionou 156 sinais produzidos espontaneamente por uma criança surda filha de pais surdos em fase de aquisição da linguagem. Os dados coletados não só confirmaram as mãos como articuladores primários da Libras, como possibilitaram a identificação uma ordem na aquisição das configurações de mão a partir da ordem apresentada na produção dos sinais.

Esses resultados de Karnopp (1999) foram os principais motivadores para a investigação sobre ordenação no registro escrito da Libras e, juntamente com as leituras e reflexões sobre simultaneidade e sequencialidade nas línguas de sinais, possibilitaram a formulação da pergunta que norteou a presente pesquisa.

Como no sistema SignWriting as características tridimensionais das línguas de sinais são preservadas - pois este faz o registro preciso de seus parâmetros fonológicos (configuração de mão, locação, movimento, 
orientação da mão e expressões não manuais) e sintáticos (uso do espaço de sinalização, referentes dêiticos e anafóricos) (QUADROS, 2004; QUADROS e KARNOPP, 2004; SUTTON, 2011) - considerou-se que seria relevante investigar a relação entre a sequencialidade na produção do sinal e no registro escrito, incluindo uma possível ordenação dos parâmetros para este último.

A hipótese da existência de uma ordenação dos parâmetros visuais no registro escrito da Libras foi apontada também em Nobre (2011), que realizou um estudo de caso com o objetivo de identificar regularidades e irregularidades na Escrita de Sinais. A "ordem dos símbolos" aparece na lista de fenômenos que Nobre alega ter observado. O estudo de caso do pesquisador consistiu na produção de 20 sinais registrados na forma escrita por quatro sujeitos selecionados para a pesquisa.

Apesar de o pesquisador alegar que "a ordem dos elementos varia de acordo com a perspectiva de quem escreve" (NOBRE, 2011, p. 159), não apresenta detalhamento desse resultado. Inclusive, apresenta a produção dos participantes da pesquisa na forma completa, isto é, com o "sinal escrito pronto", sem enfatizar ou apontar a ordem na qual foram registrados, nem mesmo comentar como concluiu que a ordem foi diferente.

Além disso, Nobre (2011) apresentou entre seus dados um quadro no qual é possível identificar uma sequência de glifos utilizada no registro do sinal escrito (quadro 1), porém não explicitou se essa sequência é uma proposta sua ou se é decorrente do que foi observado em seu estudo. O autor registra apenas que o quadro "[...] apresenta alguns parâmetros que podem ser analisados por meio da decomposição do sinal escrito através do estudo dos símbolos separados" (NOBRE, 2011, p. 165). 
Quadro 1 - Decomposição fono-morfológica dos sinais segundo Nobre

\begin{tabular}{|c|c|c|c|c|c|}
\hline Sinal & P.A & $\mathrm{CM}$ & Contato & Mov. & Legenda \\
\hline & Faca & & * & $\begin{array}{c}\text { Năo } \\
\text { necessário }\end{array}$ & $\begin{array}{l}\text { Segunda- } \\
\text { feira }\end{array}$ \\
\hline$x^{2} \times x-2 x^{4}$ & Ombro & & ** & 슬 충 & Passear \\
\hline 1 & $\begin{array}{l}\text { Espaço } \\
\text { neutro }\end{array}$ & & $\begin{array}{l}\text { NÁO } \\
\text { POSSUI }\end{array}$ & & Usar \\
\hline प्? & $\begin{array}{l}\text { Espaço } \\
\text { neutro }\end{array}$ & $\square$ & (อ) & & Faca \\
\hline
\end{tabular}

Fonte: NOBRE, 2011, p. 166

Como o autor não aprofunda a descrição do quadro (quadro 1 acima) não foi possível identificar por que o mesmo apresentou o ponto de articulação (PA) na primeira coluna. Por isso, tanto essa forma de apresentação, como o que Nobre (2011) alegou ter observado sobre a ordenação, contribuiu para reforçar o interesse despertado pela pesquisa de Karnopp (1999), de que seria relevante investigar a escrita de sinais do ponto de vista do processo ${ }^{6}$ de registro - não só do "sinal escrito pronto" - para verificar a existência ou não de um padrão de ordenação.

Apesar de a leitura ser holística, conforme já comentado, os glifos no sistema SignW riting (SW) são registrados verticalmente e relacionados entre si para formação do sinal escrito. Essa apresentação constitui a "pilha" que apresenta o todo do sinal escrito sem transparecer a ordem do registro.

A apresentação gráfica de um signo no sistema SignWriting é constituída por:

${ }^{6}$ Entendendo-se processo como a sequência de ações realizadas para produzir o sinal escrito.

7 Segundo Stumpf (2005), pilha é o sinal escrito completo. Uma maneira econômica de apresentar o sinal, inicialmente motivada pelo grande número de usuários da forma manuscrita, na qual a organização dos elementos gráficos apresenta-se na forma "empilhada". 
Retângulos virtuais [que] compreendem um conjunto de símbolos alinhados verticalmente. Um conjunto de símbolos representa um signo, quer dizer uma unidade lexical eventualmente associada a um complemento de informações gramaticais, os signos são separados por um espaço. No interior de um "signo etiqueta" ou "pilha", os símbolos são colocados verticalmente, segundo a lógica do corpo humano. Assim, o círculo que configura a cabeça suporta os símbolos que representam os elementos manuais. Os elementos não manuais (essencialmente os movimentos da face e o olhar) são inscritos dentro do círculo cabeça (BOUTORA, 2003 apud STUMPF, 2005, p. 52).

A representação estática do sinal escrito corrobora com o argumento da simultaneidade da língua de sinais enfatizada por Stokoe (1960) e vários outros pesquisadores, como Quadros e Karnopp (2004). No entanto, ao se investigar o processo de registro escrito do sinal, é possível identificar certos padrões na sequência escolhida para a escrita, como será descrito nas seções seguintes.

\section{Metodologia}

Com o objetivo de investigar a existência de padrão na sequência escolhida para registro dos glifos de um sinal escrito, elaborou-se um estudo de caso em experimento único contendo nove sinais que deveriam ser registrados de acordo com sistema SignWriting. Os nove sinais propostos foram escolhidos de maneira a contemplar diferentes realizações de configuração de mão e pontos de articulação, sem apresentar uma escrita complexa. Essa seleção de complexidade foi realizada a partir da experiência da pesquisadora enquanto ministrante de disciplinas e diversos cursos sobre Escrita de Sinais.

Os nove sinais foram distribuídos em três grupos, de acordo com o ponto de articulação. O ponto de articulação foi escolhido 
como parâmetro de distinção devido ao resultado apresentado por Nobre (conf. quadro 1 anterior), no qual se observa que nos sinais que apresentavam toque em alguma parte do corpo o primeiro parâmetro registrado foi o $\mathrm{PA}$.

Assim, foram agrupados três sinais realizados sem toque no corpo, três sinais com toque no tronco e três sinais realizados com toque na cabeça (quadro 2). Todos exigiam o uso de configurações de mão em sua realização.

Quadro 2-Glosa dos sinais apresentados às participantes do experimento

\begin{tabular}{|c|c|c|}
\hline Grupo A & Grupo B & Grupo C \\
\hline COMUNICAÇÃO & SAUDADE & SABER \\
\hline BRINCAR & MEU & INTELIGENTE \\
\hline CASA & AMOR & PERIGOSO \\
\hline
\end{tabular}

No primeirq grupo foram apresentados os sinais $s^{\mathbb{C}} \underbrace{d \uparrow}$ (COMUNICAÇÃO), produzidos no espaço neutro, sem contato com o corpo. Neste grupo observa-se que no sinal CASA as mãos realizam contato somente na ponta dos dedos, enquanto nos sinais BRINCAR e COMUNICAÇÃO não existe contato entre as mãos.

No segundo grupo foram mostrados outros três sinais que apresentavam toque no corpo, sendo este identificado por meio de um glifo que representa o ombro ( $)$, assim como nos exemplos: $\bar{\diamond}$ $(\mathrm{SAUDADE}), \bar{*}(\mathrm{MEU})$ e $\bullet \overline{\mathfrak{J}}$ (AMOR).

Finalmente, o último grupo mostrou três sinais que apresentavam toquena cabeça, comonos exemplos: $0^{* *}\left(\right.$ SABER), $\bigcirc^{\lambda}$ (INTELIGENTE) e (PERIGOSO). 
Para participar do experimento foram selecionadas quatro estudantes com nível de proficiência considerado suficiente para realizar a atividade proposta. $\mathrm{O}$ estímulo da atividade foi a apresentação do sinal pela própria pesquisadora para cada participante.

As quatro participantes selecionadas tiveram a oportunidade de aprender a escrita de sinais pela Universidade Federal de Santa Catarina (UFSC). Uma delas estudara três disciplinas de Escrita de Sinais no curso de Letras Libras a Distância pela Universidade Federal de Santa Catarina (UFSC) e ensinava escrita de sinais em cursos que ministrava; duas estudaram duas disciplinas no curso presencial pela UFSC; e a quarta informante aprendeu o sistema sozinha.

Cada participante realizou as atividades individualmente e em horário diferente das demais, a fim de garantir que a decisão sobre a ordem da escrita dos glifos fosse autônoma, sem influência de outras participantes.

Definiu-se, ainda, que as participantes recebessem nomes fictícios, e os escolhidos foram: Rosa, Violeta, Margarida e Girassol.

As sessões de coleta de dados do estudo foram registradas em vídeo, com o foco no processo de escrita. A câmera foi posicionada de modo a enquadrar somente as mãos das participantes, registrando a escrita de cada sinal no papel.

Os vídeos foram posteriormente analisados utilizando-se o software ELAN, no qual se definiu que seriam anotados cada glifo de acordo com sua ordem de escrita, bem como seria registrado o tempo de produção do sinal escrito - tanto o tempo de escrita propriamente dita, associando-se o tamanho da anotação com a duração do registro, quanto o espaço de tempo entre um registro e outro.

$\mathrm{Na}$ próxima seção apresentar-se-ão os resultados obtidos no experimento a partir da anotação dos vídeos no ELAN. 


\section{Resultados da produção escrita das participantes}

Os resultados serão apresentados de acordo com os grupos de sinais propostos na coleta de dados. Como a produção das participantes apresentou o mesmo padrão de ordenação dentro dos grupos propostos, a fim de contemplar os objetivos do presente artigo e evitar estender muito o texto, apresenta-se a descrição detalhada somente de um sinal de cada grupo.

\section{a) Registro escrito do sinal: CASA}

\section{a.1) Produção da participante Rosa}

$\mathrm{O}$ primeiro parâmetro registrado foi o da configuração da mão esquerda, em que (E) significa a esquerda e (D) significa a direta, depois a participante definiu o preenchimento da metade do glifo. Em seguida, colocou outra configuração da mão direita e, finalmente, registrou os dois glifos de contato (figura 2).

Figura 2 - Anotação em glosas e transcrição em SW da produção 1 de Rosa

\begin{tabular}{|c|c|c|c|c|}
\hline $\begin{array}{l}00: 03: 19.000 \quad 00: 03: 20.000 \\
\text { |configuraçä̀o da măo (E) }\end{array}$ & $00: 03: 21.000$ & $\begin{array}{l}00: 03: 22.000 \quad 00: 03: 23.000 \\
\text { |configuraçăo da măo (D) }\end{array}$ & $00: 03: 24.000$ & $\begin{array}{l}\text { 00:03:25.000 } \\
\text { |dois contatos }\end{array}$ \\
\hline & & & & $* *$ \\
\hline
\end{tabular}

\section{a.2) Produção da participante Violeta}

Violeta também registrou primeiro a configuração da mão esquerda, depois a configuração direita e, por último, os dois glifos de contato (figura 3). 
Figura 3 - Anotação em glosas e transcrição em SW da produção 1 de Violeta

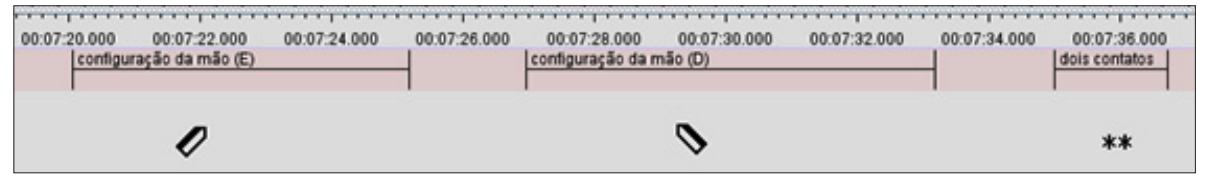

\section{a.3) Produção da participante Margarida}

No caso de Margarida, destaca-se que o primeiro glifo anotado tenha sido o correspondente à configuração da mão esquerda. Em seguida observa-se um intervalo entre os registros, que marca o tempo que a participante olha a mão para definir a orientação da palma e, consequentemente, o preenchimento do glifo, decidindo preencher a metade.

Após o preenchimento do glifo correspondente à mão esquerda, a participante registra e preenche o glifo correspondente à mão direita, em intervalo de tempo menor.

Finalmente, registrou os dois glifos de contato (figura 4).

Figura 4 - Anotação em glosas e transcrição em SW da produção 1 de Margarida

\begin{tabular}{|c|c|c|c|}
\hline 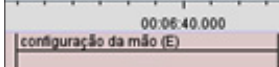 & ónests & 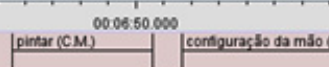 & 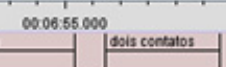 \\
\hline 0 & & 0 & ** \\
\hline
\end{tabular}

\section{a.4) Produção da participante Girassol}

A ordem seguida foi a mesma das três participantes anteriores, mas Girassol não preencheu o glifo para representar a orientação da palma no glifo de configuração de mão.

Girassol apresentou, ainda, outra diferença na produção em relação às demais participantes: registrou somente um glifo de contato (figura 5). 
Figura 5 - Anotação em glosas e transcrição em SW da produção 1 de Girassol

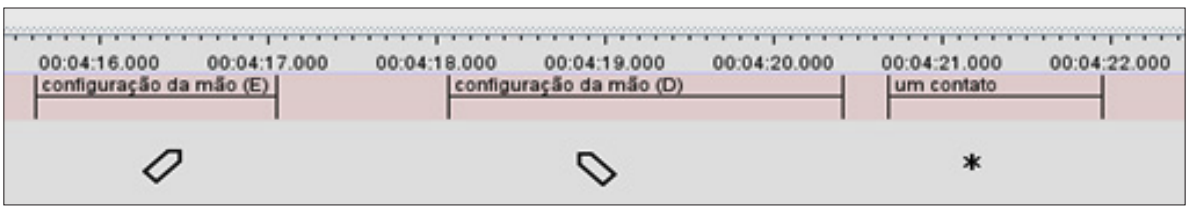

$\mathrm{O}$ quadro a seguir (quadro 3) sintetiza a produção de cada participante no registro escrito do sinal CASA.

Quadro 3 - Síntese do registro do sinal CASA de acordo com a ordem da escrita

\begin{tabular}{|c|c|c|c|}
\hline Participantes & $\begin{array}{c}1^{\circ} \text { parâmetro } \\
\text { registrado }\end{array}$ & $\begin{array}{c}2^{\circ} \text { parâmetro } \\
\text { registrado }\end{array}$ & $\begin{array}{c}3^{\circ} \text { parâmetro } \\
\text { registrado }\end{array}$ \\
\hline Rosa & $\varnothing$ & & $* *$ \\
\hline Violeta & $\varnothing$ & & $* *$ \\
\hline Margarida & $\theta$ & & $* *$ \\
\hline Girassol & $\nabla$ & & * \\
\hline
\end{tabular}

Os outros dois sinais, também do grupo A - COMUNICAÇÃO e BRINCAR -, apresentaram a mesma ordem de registro observada no sinal CASA.

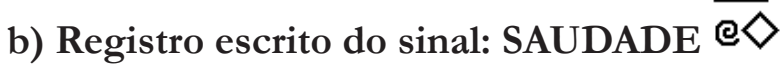

\section{b.1) Produção da participante Rosa}

A participante Rosa registrou primeiramente o contorno de um retângulo e, em seguida, realiza o preenchimento da forma constituindo o primeiro glifo, correspondente ao parâmetro Ponto de Articulação (PA) para "ombro". 
Em seguida, registra o glifo correspondente à configuração da mão e, por último, o glifo de contato (figura 6).

Figura 6 - Anotação em glosas e transcrição em SW da produção 4 de Rosa

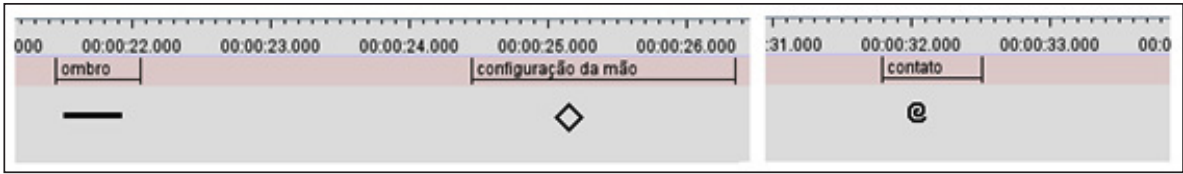

\section{b.2) Produção da participante Violeta}

Assim como Rosa, Violeta também iniciou registrando o glifo correspondente ao PA "ombro", seguido dos glifos correspondentes à configuração da mão e contato, nessa ordem (figura 7).

Figura 7 - Anotação em glosas e transcrição em SW da produção 4 de Violeta

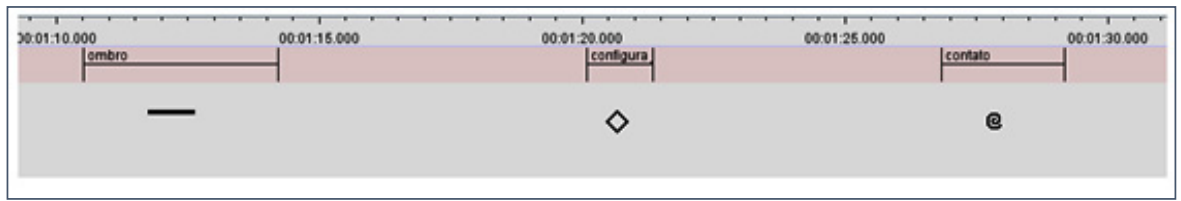

\section{b.3) Produção da participante Margarida}

Assim, como Rosa e Violeta, Margarida também registrou primeiro o glifo correspondente ao PA "ombro", seguido dos glifos correspondentes à configuração da mão e contato, nessa ordem (figura 8).

Figura 8 - Anotação em glosas e transcrição em SW da produção 4 de Margarida

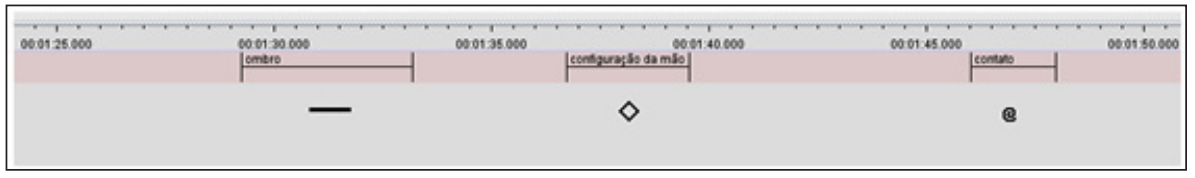




\section{b.4) Produção da participante Girassol}

Girassol manteve o padrão apresentado por Rosa, Violeta e Margarida, registrando primeiro o glifo correspondente ao PA “ombro", seguido dos glifos correspondentes à configuração da mão e contato, nessa ordem (figura 9).

Figura 9 - Anotação em glosas e transcrição em SW da produção 4 de Girassol
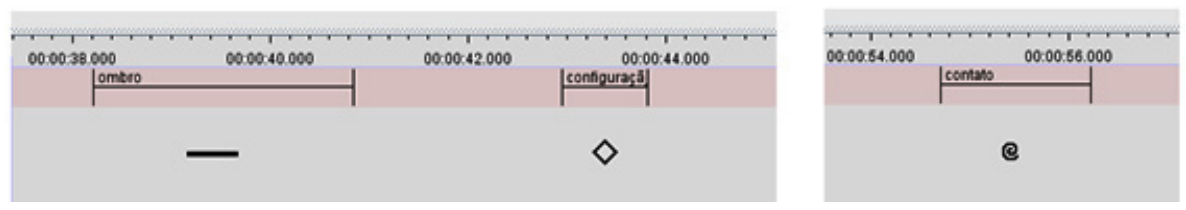

O quadro a seguir (quadro 4) sintetiza a produção de cada participante no registro escrito do sinal SAUDADE.

Quadro 4 - Síntese do registro do sinal SAUDADE de acordo com a ordem da escrita

\begin{tabular}{|c|c|c|c|}
\hline Participantes & $1^{\circ}$ parâmetro & $2^{\circ}$ parâmetro & $3^{\circ}$ parâmetro \\
\hline Rosa & & & 巳 \\
\hline Violeta & & & 巳 \\
\hline Margarida & & & e \\
\hline Girassol & & & 巳 \\
\hline
\end{tabular}

Os outros dois sinais, também do grupo B - MEU e AMOR -, apresentaram a mesma ordem de registro observada no sinal SAUDADE. 


\section{c) Registro escrito do sinal: SABER}

\section{$0^{*} *^{3}$}

\section{c.1) Produção da participante Rosa}

Rosa começou registrando o glifo correspondente ao PA "cabeça", e depois delimitou o local onde seria realizado o toque na testa $\left[\mathrm{O}_{\text {] }}\right.$.

Em seguida, registrou o glifo correspondente à configuração da mão, e marcou uma linha para definir o limite do preenchimento do glifo de modo a determinar a orientação da mão [ $]$.

Por último, registrou os glifos correspondentes ao contato [ $* *$ ]. Estes determinam que exista um toque na área delimitada da cabeça (no caso, a testa), e configuram o sinal registrado em pilha (figura 10).

Figura 10 - Anotação em glosas e transcrição em SW da produção7 de Rosa

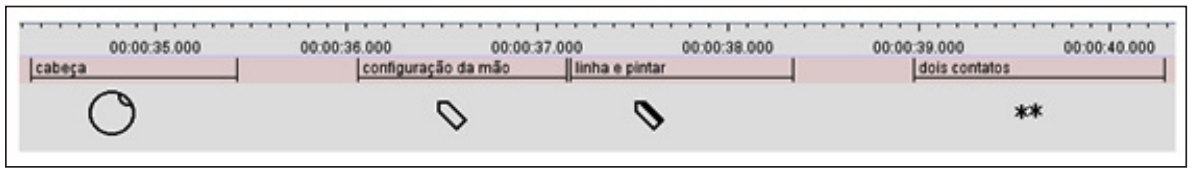

\section{c.2) Produção da participante Violeta}

Violeta apresenta uma sequência de registro semelhante à de Rosa. Começou registrando o glifo correspondente ao PA "cabeça", e depois delimitou o local onde seria realizado o toque na testa.

Em seguida, registrou o glifo correspondente à configuração da mão. No entanto, ao invés de realizar o preenchimento deste último glifo, registrou, em seguida, os glifos correspondentes ao contato.

Somente depois de registrar o contato a participante retornou ao glifo correspondente à configuração de mão, e realizou o preenchimento de modo a determinar a orientação da mão (figura 11). 
Figura 11 - Anotação em glosas e transcrição em SW da produção 7 de Violeta

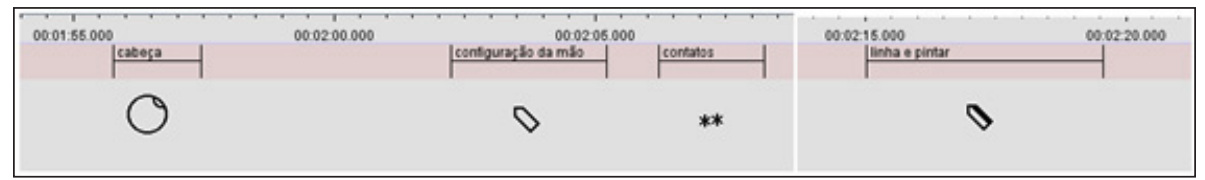

\section{c.3) Produção da participante Margarida}

Margarida apresentou a mesma sequência de registro de Violeta (figura 12).

Figura 12 - Anotação em glosas e transcrição em SW da produção 7 de Margarida

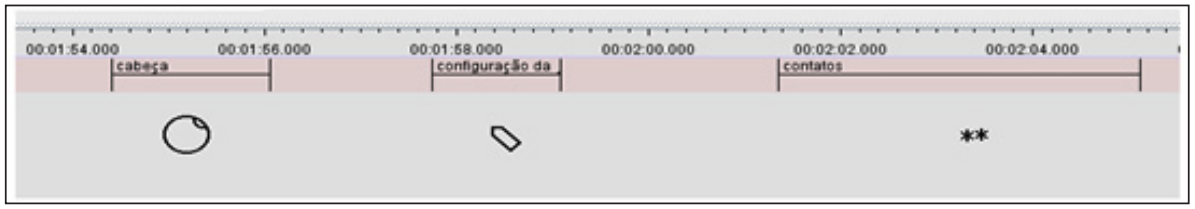

A diferença foi que a participante não preencheu o glifo correspondente à configuração de mão. Isso pode ter ocorrido por esquecimento ou por decisão que a orientação da palma ficaria em branco para representar a última configuração na posição de contato de acordo com a perspectiva do sinalizador (figura 13).

Figura 13 - Possibilidades de registro do sinal SABER de acordo com a orientação da palma

\begin{tabular}{ll|} 
Locaçào inicial com a visão de \\
metade do dorso e palma da mão até \\
o final ao tocar a cabeça.
\end{tabular}


$\mathrm{Na}$ figura 13, observa-se que a locação inicial se dá quando ainda não houve o contato na cabeça, enquanto a informante levanta o braço e olha diretamente a mão para observar qual lado é visualizado e definir se há necessidade de preenchimento - pintando de preto um dos lados, deixando o outro lado em branco, por estar se preparando para a produção propriamente dita do sinal.

O glifo que representa a configuração de mão é diferente na locação final, porque, após o contato na cabeça, o sinalizador olha a forma da mão e verifica a orientação da palma (para baixo), definindo que o glifo não deve ser preenchido.

\section{c.4) Produção da participante Girassol}

Girassol, assim como Margarida, apresentou a sequência de registro do glifo correspondente ao PA "cabeça" e depois delimitou o local onde seria realizado o toque na testa, registrando, em seguida, o glifo correspondente à configuração da mão (figura 14).

Figura 14 - Anotação em glosas e transcrição em SW da produção 7 de Girassol

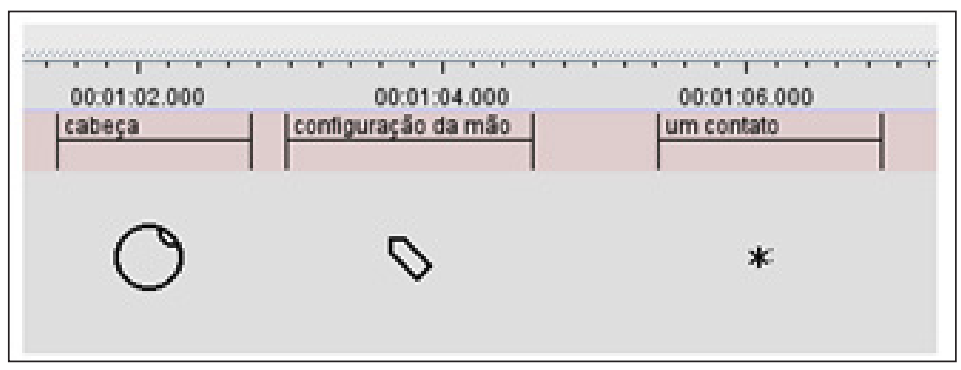

Tal como Margarida, Girassol também não preencheu o glifo correspondente à configuração de mão.

A diferença da produção de Girassol está na quantidade de glifos para representar o contato: registrou apenas um glifo. Isso também a diferencia de Rosa e Violeta - que registraram dois glifos. 
Pode-se observar, ainda, que o intervalo de tempo entre o registro de cada glifo é menor na produção de Girassol.

O quadro a seguir (quadro 5) sintetiza a produção de cada participante no registro escrito do sinal SABER.

Quadro 5 - Síntese do registro do sinal SAUDADE de acordo com a ordem da escrita

\begin{tabular}{|c|c|c|c|}
\hline Participantes & $1^{\circ}$ parâmetro & $2^{\circ}$ parâmetro & $3^{\circ}$ parâmetro \\
\hline Rosa & $\bigcirc$ & $\nabla$ & $* *$ \\
\hline Violeta & $\bigcirc$ & $\nabla$ & $* *$ \\
\hline Margarida & $\bigcirc$ & $\triangleright$ & $* *$ \\
\hline Girassol & $\bigcirc$ & $\varnothing$ & $*$ \\
\hline
\end{tabular}

Conclui-se a apresentação dos resultados obtidos destacando que as quatro participantes apresentaram uma sequência de registro do sinal muito semelhante. Na seção seguinte serão discutidos os resultados com base na pergunta de pesquisa e na revisão de literatura realizada.

\section{Discussão dos resultados: Escrita de Sinais também tem influência de simultaneidade temporal?}

A hipótese inicial da presente pesquisa era de que, apesar da realização simultânea de vários sinais da Libras, o registro escrito dos mesmos deveria exigir que o sujeito estabelecesse uma sequência de ordenação dos glifos correspondentes aos parâmetros visuais.

Os resultados da produção das participantes para os sinais do grupo 1 evidenciaram que, no caso de sinais que não apresentam toque 
no corpo - conhecidos como sinais realizados em espaço neutro ${ }^{8}-$, o primeiro parâmetro registrado é a configuração de mão.

Esse resultado concorda com o observado por Karnopp (1999). A partir dos dados de criança surda em fase de aquisição da linguagem, a pesquisadora definiu que os articuladores primários das línguas de sinais seriam as configurações de mão. Lembrando que Karnopp (1999) destacou a produção dos sinais sem considerar a produção da escrita de sinais.

No entanto, a argumentação inicial de que seria pouco provável que alguém iniciasse o registro de um glifo, parasse, registrasse outro, e retomasse o registro do anterior, precisou ser relativizada. Pois a participante Violeta, ao escrever o sinal SABER, registrou o glifo correspondente à configuração da mão, mas, ao invés de realizar o preenchimento deste glifo para marcar a orientação da palma no passo seguinte, registrou outro glifo correspondente ao contato. Somente depois de registrar o contato, a participante retornou ao glifo correspondente à configuração de mão e realizou o preenchimento de modo a determinar a orientação da mão (figura 11 apresentada anteriormente).

Esse resultado não contraria a hipótese, visto que o glifo correspondente à configuração de mão não foi interrompido, seu registro sem o preenchimento seria suficiente para o registro do sinal escrito, conforme apresentado pelas participantes Margaria e Girassol (figuras 13 e 14 apresentadas anteriormente). O que se verifica é que o resultado comprova a existência do fenômeno de "empilhamento" observada por outros pesquisadores, como Stumpf (2005) e Nobre (2011), por exemplo. No registro dos glifos para compor um sinal, não se repete glifos para marcar outros parâmetros sem antes verificar se é possivel aproveitar os já registrados para realizar pequenos acréscimos, de modo a sintetizar o registro do sinal. Quando for possível aproveitar um glifo existente para "empilhar" outro parâmetro, a oportunidade deverá ser aproveitada.

8 Conforme proposta de Ferreira (1995), na qual o ponto de articulação é chamado de "espaço neutro" nos casos em que não há toque no corpo, ou ainda, nos quais o ponto onde o sinal é realizado não é relevante. 
Portanto, caso seja encontrado resultado semelhante ao de Violeta em pesquisas futuras, tal fenômeno poderá contribuir para a discussão da relação de dependência entre os parâmetros configuração de mão e orientação da palma.

Por outro lado, nos grupos de sinais $\mathrm{B}$ e $\mathrm{C}$, que apresentavam toque na cabeça e no tronco, respectivamente, observou-se que a configuração de mão não foi o primeiro parâmetro registrado, e sim o ponto de articulação.

Esse resultado indica que, ao registrar sinais que apresentam toque em algum lugar do corpo, com exceção do toque nas mãos, parece ser mais intuitivo delimitar primeiramente a região na qual o sinal se realiza. Além disso, os glifos que representam cabeça e ombro são produtivos e considerados de fácil reprodução - para o primeiro, cabeça, basta traçar uma circunferência, e no segundo, ombro, um retângulo preenchido com o maior lado na disposição horizontal (figura 15).

Figura 15 - Glifos correspondestes aos pontos de articulação cabeça e ombro

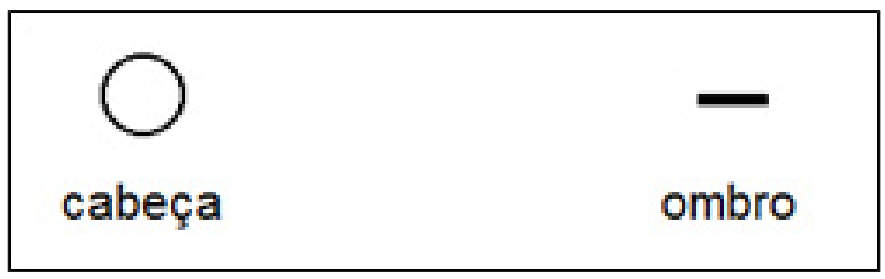

Sobre a complexidade dos parâmetros configuração de mão e ponto de articulação os pesquisadores Brentari e Wilbur (2008) argumentam que:

As mãos, portanto, podem codificar muito mais aspectos do evento do que o corpo. As mãos são muito mais versáteis que o corpo: primeiro, as mãos podem moverse no espaço; segundo, elas podem assumir diferentes configurações de mão; terceiro, elas formam um par. O componente movimento, em si mesmo, é complexo por incluir a maneira e a direção do movimento. O corpo, ao 
contrário, não demonstra nenhuma destas propriedades. O corpo não se move da mesma maneira que as mãos e só existe um corpo. Deste modo, o corpo codifica um número consideravelmente menor de aspectos do evento. (BRENTARI e WILBUR, 2008, p. 86, grifos nossos).

O parâmetro configuração da mão na escrita de sinais tem mais possibilidades de combinações do que o local corpo. Tem-se 61 CMs (Pimenta, 20119) - ou 73 CMs (Lira e Souza, 2005) - diferentes, enquanto no corpo há 12 regiões principais de localização (Ferreira, 1995). Provavelmente, o menor número de possibilidades de combinações é o fator que contribui para a decisão de registrar primeiro o local do corpo envolvido na produção do sinal, principalmente se tiver o toque na cabeça ou ombro.

Apesar de reconhecer que é preciso ampliar os dados, tanto com relação ao número de participantes quanto ao número de sinais propostos, a observação de Brentari e Wilbur (2006) corrobora com a hipótese de que no caso de sinais que realizam contato com o corpo o primeiro parâmetro registrado na escrita será o ponto de articulação.

Ou ainda, de acordo com os resultados encontrados no experimento: nos sinais que não apresentam toque em alguma parte do corpo (grupo A), o primeiro parâmetro registrado será a configuração da mão; nos sinais que apresentam toque no tronco (grupo B), o primeiro parâmetro registrado será o ponto de articulação, com o glifo correspondente ao local ombro; nos sinais que apresentam toque na cabeça (grupo C), o primeiro parâmetro registrado será o ponto de articulação, com o glifo correspondente ao local cabeça.

Como as mãos são mais versáteis, os glifos correspondentes às configurações de mão são diversificados, o que implica em mais tempo

9 Inicialmente, as $61 \mathrm{CMs}$ identificadas por Pimenta não tinham registro de data, pois apresentavam-se em uma espécie de pôster e nos materiais comercializados pela LSB Vídeo desde meados da década de 90, como no "jogo das configurações da mão". O material foi registrado posteriormente e passou a ser referenciado pelo registro de 2011. 
para a análise e definição do glifo mais adequado no registro escrito do sinal. Apesar de não estar detalhado no presente texto, é possível observar que o registro dos glifos correspondentes à configuração de mão exige um tempo maior de reflexão.

O tempo de registro, principalmente o intervalo entre a escrita de cada glifo, é um ponto relevante que deve ser aprofundado futuramente.

Também foi possível observar nos dados que, apesar de as participantes serem destras - no sinal CASA, realizado com duas mãos -, todas iniciaram o registro do sinal pela configuração da mão esquerda ${ }^{10}$ (figuras 2, 3, 4 e 5).

Poderia se levantar a hipótese de que isso ocorre por influência da escrita do português - ordenação da esquerda para direta. No entanto, a observação dos dados e a experiência em sala de aula parecem indicar que isso ocorre em função de a mão forte da lateralidade ${ }^{11}$ (no caso dos destros, a direita) estar ocupada com a escrita do glifo. Ou seja, enquanto o sujeito segura o lápis ou caneta para escrever (com a mão que prevalece de acordo com sua lateralidade), a outra fica livre para reproduzir a configuração de mão (no caso de destros, a mão esquerda), e essa é a primeira observada e registrada.

Sobre essa hipótese reconhece-se também a necessidade de ampliação dos dados incluindo sinais que apresentem duas configurações de mão distintas - diferente dos sinais simétricos apresentados no experimento. Tal investigação poderá indicar uma sub-ordenação no registro escrito dos sinais ${ }^{12}$.

\footnotetext{
${ }^{10}$ A informação de que as participantes eram destras só foi verificada depois da observação dos dados. Em experimentos futuros planeja-se selecionar tanto participantes destros quanto canhotos, a fim de verificar a existência de padrão em informantes com lateralidade distinta.

11 "A lateralidade é a dominância de um lado do corpo em relação ao outro no que diz respeito à força e precisão [...]" (MENDES, 2001, p. 39).

${ }^{12} \mathrm{O}$ experimento apresentou somente sinais de uma mão ou sinais de duas mãos com simetria por considerar que estes seriam mais simples para as participantes. Como não era o foco verificar a sub-ordenação de cada parâmetro considerou-se desnecessário investigar sinais não-simétricos neste momento.
} 


\section{Considerações Finais}

A experiência de uma das autoras como participante no curso de Pós-Graduação em Linguística na UFSC, enquanto professora da disciplina Escrita de Sinais, motivou a investigação sobre a ordenação na escrita da Libras.

A comparação dos resultados obtidos com os resultados encontrados na revisão de literatura indicou algumas convergências e divergências.

No caso de sinais realizados no espaço neutro, sem toque no corpo, observou-se que o primeiro parâmetro registrado foi a configuração de mão, concordando com a afirmação de Karnopp (1999) sobre a relevância desse parâmetro nas línguas de sinais.

Os resultados encontrados (quadro 6) discordaram do que afirmou Nobre (2011) ao registrar que não haveria padrão na ordenação dos parâmetros na escrita de sinais. Apesar dessa afirmação, o mesmo autor apresentou um quadro síntese (quadro 1 apresentado anteriormente) no qual o ponto de articulação foi o primeiro parâmetro registrado nos casos de sinais que apresentavam toque em alguma região do corpo.

Quadro 6 - Síntese do registro de todos os sinais segundo ordem do registro

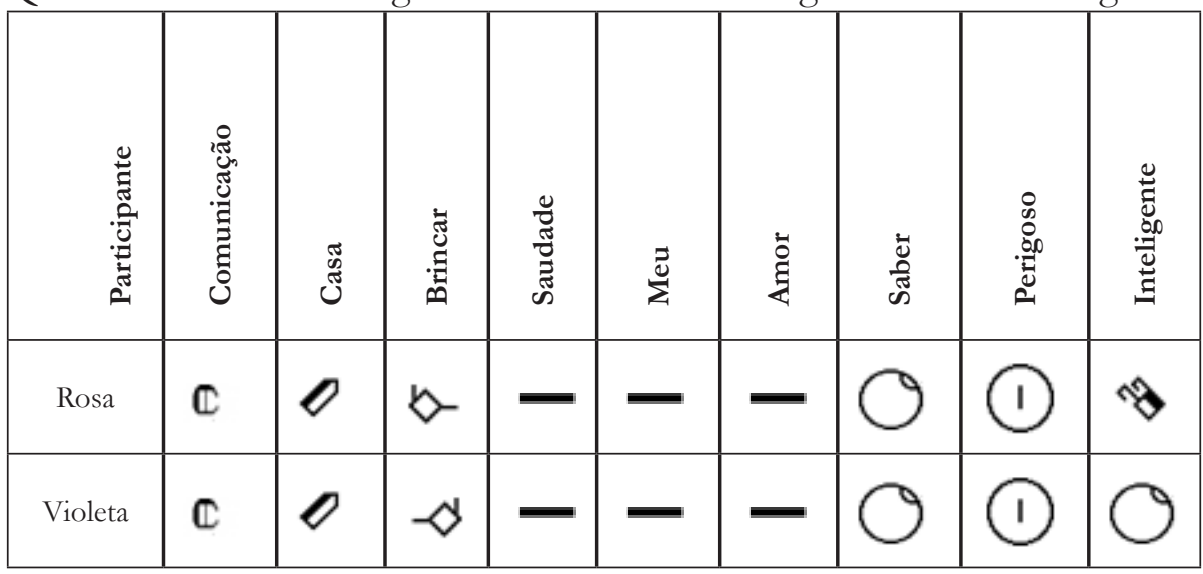




\begin{tabular}{|l|l|l|l|l|l|l|l|l|l|}
\hline Margarida & $\mathbb{C}$ & $\boldsymbol{D}$ & $\diamond$ & - & - & - & 0 & 0 & 0 \\
\hline Girassol & $\mathbb{C}$ & 0 & $\diamond$ & - & - & - & 9 & 1 & 0 \\
\hline
\end{tabular}

O quadro 6 indica que possivelmente haverá um padrão na ordem de registro do glifo em cada sinal. Somente no caso do sinal INTELIGENTE a participante Rosa registrou primeiro a configuração da mão, mas, nos outros dois, a mesma participante manteve o padrão encontrado nos três sinais das participantes Violeta, Margarida e Girassol.

Deduz-se, com base na análise dos dados apresentados por Nobre (2011), que o mesmo não considerou o processo de registro do sinal, pois seus resultados apresentam somente o sinal escrito completo (pilha), sem mencionar como foi observada a ordenação. Considera-se, ainda, que talvez a ordenação a que o autor se refere esteja relacionada com a ordem de apresentação dos glifos na pilha.

As investigações de Karnopp (1999) e Nobre (2011) são as que mais se aproximaram da presente proposta de pesquisa. Não foi localizada outra pesquisa que registrasse o processo de escrita para discutir a ordem de registro dos parâmetros.

Acredita-se que a identificação de padrões na escrita de sinais pode contribuir para a elaboração de uma proposta didática adequada ao que seria "mais natural" para os aprendizes. Os resultados, ainda que iniciais, desta pesquisa possibilitaram, por exemplo, a produção de uma atividade "caça-sinais", conforme apresentada na figura 16 abaixo: 
Figura 16 - Atividade "caça-sinais" elaborada pela autora ${ }^{13}$

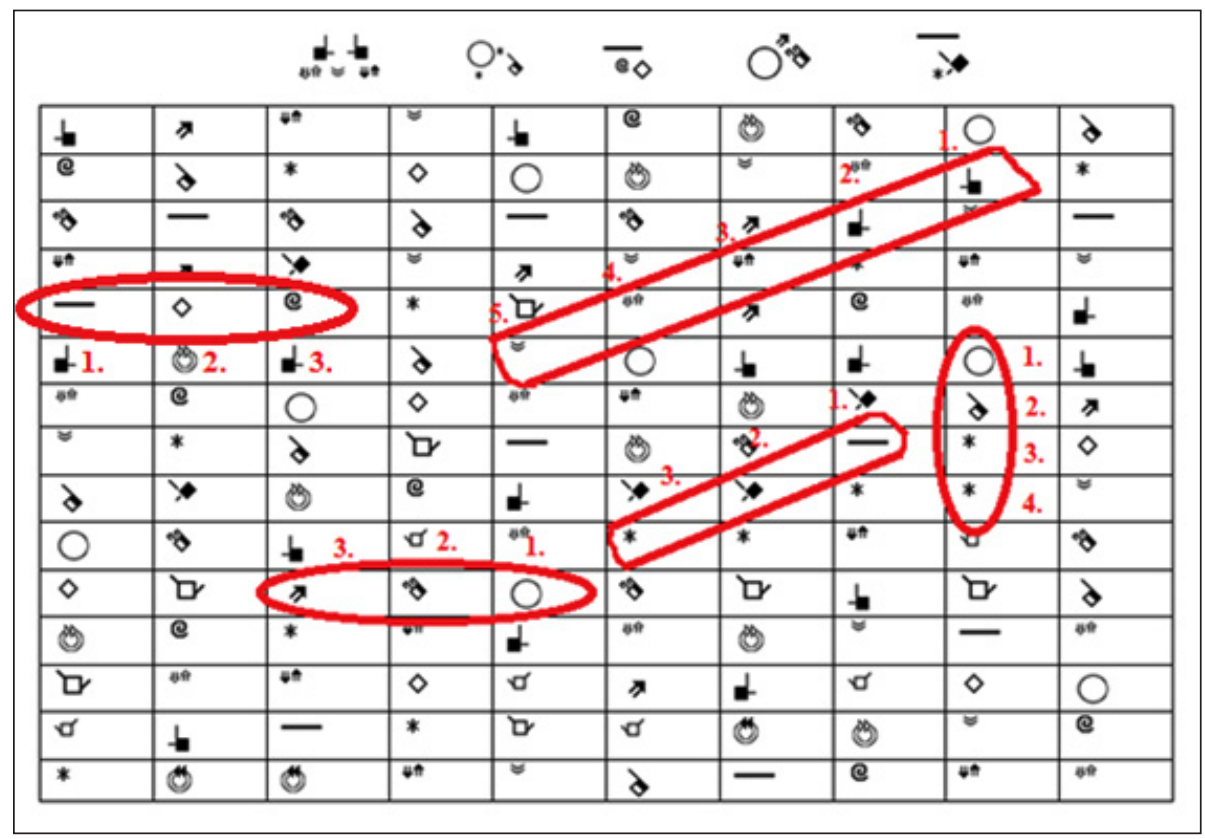

Acredita-se que o aprofundamento dessa investigação contribuirá também para a alfabetização em escrita de sinais, além da organização e ordenação de dicionários, pois será possível estabelecer um padrão para a ordenação dos parâmetros de um sinal a partir do registro escrito dos glifos correspondentes à sequência na escrita de sinais, que antes era desconhecida.

${ }^{13}$ Essa atividade foi aplicada a outros participantes (alunos da disciplina de Escrita de Sinais). Os estudantes demonstraram interesse na novidade da atividade porque antes não tinham pensado qual seria a ordem de registro da escrita de sinais determinante para localizar o sinal escrito no quadro proposto. Os que identificaram algum sinal observaram um padrão de registro e rapidamente localizaram os outros sinais escritos. Depois de realizar essa atividade, os próprios estudantes elaboraram outras atividades semelhantes, tendo como base a ordenação dos glifos no registro escrito da língua de sinais. 
A escrita de sinais é um registro escrito de uma língua falada por meio de sinais. Pude mostrar os aspectos teóricos ligados com a minha reflexão e com os parâmetros da língua de sinais.

\section{Referências}

ALDRETE, M. C. Gramática da Língua de Sinais Mexicana. 2008. 1122 p. Tese (Doutorado em Linguística). El Colégio de México. Centro de Estudos Linguísticos e Literários, México, 2008.

BARRETO, M. BARRETO, R. Escrita de Sinais sem mistérios. Belo Horizonte: Ed. Do autor, 2012.

BIANCHINI, C.S.; BORGIA, F. 'Writing Sign languages: analysis of the evolution of the SignWriting system from 1995 to 2010, and proposals for future developments". Proc. International Jubilee Congress of the Technical University of Varna, Chapter: volume 6, Publisher: Technical University of Varna, Editors: O. Farhi, 2012. p.118-123.

BRENTARI, D. WILBUR, R. "Um estudo interlinguístico de segmentação da palavra em três línguas de sinais". In: QUADROS, R.; VASCONCELlOS, M. L. (Orgs.). Questões Teóricas das Pesquisas em Línguas de Sinais (TISLR 9). Petrópolis, RJ: Editora Arara Azul, 2008. p. 52-64. [Traduzido por Maria Lúcia Vasconcellos, Elaine Espíndola, Thiago Blanch Pires e Carolina Vidal Ferreira].

CALVET, L. Tradição Oral \& Tradição Escrita. São Paulo: Parábola Editorial, 2011.

CAPOVILLA, F.C. RAPHAEL, W. D. e MAURICIO, A. C. L. Novo DeitLibras: Dicionário Enciclopédico Ilustrado Trilíngue da Língua de Sinais 
Brasileira (LIBRAS) baseado em Linguística e Neurociências Cognitivas, Volume 2: Sinais de A a H. São Paulo: Editora da Universidade de São Paulo. 2009.

Novo Deit-Libras: Dicionário Enciclopédico Ilustrado Trilíngue da Língua de Sinais Brasileira (LIBRAS) baseado em Linguística e Neurociências Cognitivas, Volume 2: Sinais de I a Z. São Paulo: Editora da Universidade de São Paulo. 2009.

FERREIRA, L. Por uma gramática da língua de Sinais. Rio de Janeiro: Tempo Brasileiro, 2010. [reimpressão do texto de 1995].

FINAU, R. A. Os sinais de tempo e aspecto na LIBRAS. 2004. 249p. Tese (Doutorado em Letras) - Universidade Federal do Paraná. Curso de Pós-Graduação em Letras, na Área de Estudos Linguísticos, Setor de Ciências Humanas, Letras e Artes, Curitiba,2004.

GALEA, M. SignWriting (SW) of Maltese Sign Language (LSM) and is development into an orthography: Linguistic considerations. A dissertation submitted in fulfilment of the requirements for the degree of Doctor of Philosophy in Linguistics, Institute of Linguistics, University of Malta, Malta, 2014.

KARNOPP, L. Aquisição fonológica na língua brasileira de sinais: estudo longitudinal de uma criança surda. 1999. 273 p. Tese (Doutorado em Letras) - Pontifícia Universidade Católica do Rio Grande do Sul. Faculdade de Letras. Programa de Pós-Graduação em Letras, Porto Alegre, 1999.

LIDDELL, S. "Think and Believe: Sequentiality in American Sign Language”. Language, Washington, D.C., v. 60, n.2, p. 372-99, jun. 1984. 
. JOHNSON, R. E. "American Sign Language: The Phonological Base”. Sign Language Studies. v. 64, 1989.

LIRA, G. A.; SOUZA, T. A. F. Dicionário Digital da Língua Brasileira de Sinais - Libras. Versão 2.0. Rio de Janeiro: 2005. Disponível em: <www. ines.org.br> e <www.acessobrasil.org.br>. Último acesso em 08 dez. 2014.

MENDES, M. R. P. Avaliação Psicomotora em crianças com lesão cerebral: uma abordagem fisioterapêutica. 2001. 139 p. Dissertação (Mestrado em Educação). Campinas: Universidade Estadual de Campinas. Faculdade de Educação, 2001.

NOBRE, R. S. Processo de grafia da língua de sinais: uma análise fono-morfológica da escrita em signwriting. 2011. 201 p. Dissertação (Mestrado em Linguística) - Universidade Federal de Santa Catarina, Centro de Comunicação e Expressão, Programa de Pós-Graduação em Linguística, Florianópolis, 2011.

PIMENTA, N. Configurações de mãos em LIBRAS. Rio de Janeiro RJ: Editora LSB Vídeo, 2011. ISBN 978-85-60221-12-7.

QUADROS, R. Um capítulo na história do SignWriting. 2004. Disponível em: <http://www.signwriting.org/librar/history/>

.; KARNOPP, L. Língua de sinais brasileira: estudos linguísticos. Porto de Alegre: Artmed, 2004.

.; VASCONCELlOS, M. L. (Orgs.). Questões Teóricas das Pesquisas em Línguas de Sinais (TISLR 9). Petrópolis, RJ: Editora Arara Azul, 2008. [Traduzido por Maria Lúcia Vasconcellos, Elaine Espíndola, Thiago Blanch Pires e Carolina Vidal Ferreira]. 
SILVA, F. I. da. Analisando o processo de leitura de uma possível escrita da língua brasileira de sinais: Signwriting. 2009. $114 \mathrm{f}$. Dissertação (Mestrado em Educação) - Universidade Federal de Santa Catarina, Centro de Ciências da Educação. Programa de Pós-Graduação em Educação, Florianópolis, 2009.

STOKOE, W.C. Sign Language structure: An Outline of the Visual Communication Systems of the American Deaf. Journal of Deaf Studies and Deaf Education vol.10 n.1. Oxford University Press, 2005.

Sign Language structure. revised ed. Silver Spring: Linstok Press [1960] 1978.

STUMPF, M. R. Aprendizagem de Escrita de Língua de Sinais pelo Sistema Signwriting: Línguas de Sinais no papel e no computador. 2005. 277 p. Tese (Doutorado em Informática na Educação) - Universidade Federal do Rio Grande do Sul. Faculdade de Educação. Programa de pósgraduação em Informática na Educação, Porto Alegre 2005.

. WANDERLEY. Quem fala português, escreve em português. Quem fala inglês, escreve em inglês. Os surdos: em que língua escrevem? Revista Letras Raras. v. 5, n. 1, 2016.

SUTTON. V. Lesson in SignWriting - Textbook. La Jolla: The SignWriting Press. 1995.

. The SignWriting alphabet: The International SignWriting Alphabet 2010, ISWA 2010. La Jolla: The SignWriting Press. Retrieved February 27, 2011. Disponível em: <http:/ / www.signwriting.org/archive/ docs7/sw0636_SignWriting_Alphabet_Manual_2010.pdf> 
WANDERLEY, D. A Leitura e Escrita de Sinais de forma processual e lúdica. Curitiba: Editora PRISMAS, 2015.

XAVIER, A. N. "Um estudo da alternância no número de articulares manuais envolvidos na produção dos sinais". Anais do XVI Seminário de Teses em Andamento (SETA). Instituto de Estudos da Linguagem da UNICAMP. v. 5, 2011.

ZESHAN, U. “Towards a notion of 'word' in sign languages". In: DIXON, Robert M. W.; AIKHENVALD, Alexandra Y. Word: a cross-linguistic typology (Eds.). New York: Cambridge University Press, 2002. 